\title{
Cycas Taxa in Sri Lanka and their Morphological Characteristics of Taxonomic Significance
}

\author{
Asanka Mudannayake ${ }^{1,2}$, Suneth S. Sooriyapathirana ${ }^{3}$, Preminda Samaraweera ${ }^{3}$ and Anoma Perera ${ }^{2 *}$ \\ ${ }^{1}$ Postgraduate Institute of Science, University of Peradeniya, Sri Lanka. \\ ${ }^{2}$ Department of Botany, Faculty of Science, University of Peradeniya, Sri Lanka. \\ ${ }^{3}$ Department of Molecular Biology and Biotechnology, University of Peradeniya, Sri Lanka. \\ Accepted July 11, 2015
}

\begin{abstract}
Cycads are a primitive group of living seed plants which dignifies as an indispensable element in revealing evolutionary affinities of present day plants. However, cycads in Sri Lanka have received the least scientific attention so far. Aiming to identify the different cycad taxa present in Sri Lanka, to find out their vegetative and reproductive morphological features of taxonomic significance and to develop keys to identify these taxa, an island wide survey of Sri Lankan cycads was conducted. During the field survey, vegetative and reproductive morphological features (both qualitative and quantitative) of sixty Cycas plants were recorded. These plants were identified according to more recent, validly published circumscriptions of given taxa. Results revealed that Cycas species in Sri Lanka represent both subsection Cycas Greuter and subsection Rumphiae K. D. Hill of the section Cycas. This study further revealed the occurrence of $C$. nathorstii J. Schuster of the subsection Cycas in Sri Lanka. Accordingly, taxonomically useful morphological features in distinguishing different Cycas subsections were identified, and the taxonomic features of $C$. nathorstii were described. However, the individuals examined in both subsections showed wide but consistent variations, indicating the presence of more than a single species or several varieties in these subsections. Therefore, further investigations are needed to describe Sri Lankan Cycas species. Molecular characterization of Sri Lankan Cycas species would benefit in identifying different Cycas species of Sri Lanka and their intermediate forms, as well as in describing their biogeographic affinities and these are now being conducted at the University of Peradeniya, Sri Lanka.
\end{abstract}

Keywords: Cycas nathorstii, cycads, reproductive morphology, vegetative morphology.

\section{INTRODUCTION}

Cycads (Order: Cycadales) of Sri Lanka have received poor scientific attention over the past years though these represent an important link describing the biogeographic and evolutionary lineages of land plants. Cycads are a primitive group of living seed plants which have been in existence for more than 250 million years (Mamay, 1969). All cycad species are distributed in tropical, subtropical and warm temperate regions of both the northern and southern hemispheres. There are 331 validly-published species in this order belonging to 10 genera; Bowenia, Ceratozamia, Cycas, Dioon, Encephalartos, Lepidozamia, Macrozamia, Microcycas, Stangeria, and Zamia (Osborne et al., 2012). Of these, Cycas L. is the sole living cycad group in Asia (Lindstrom and Hill, 2007). Species of this genus belong to the unigeneric family Cycadaceae, and are considered as the basal lineage of all living cycads (Stevenson, 1992). About 100 species are reported for the genus Cycas worldwide, and around 40 species occur in Indo-Chinese region (Lindstrom and Hill, 2007). Of all Asian countries, the highest Cycas species richness of 24 species is reported from Vietnam followed by China and
Thailand with 21 and 10 species respectively (Hill et al., 2003). However, most of the Cycas populations are declining due to uncontrolled human activities, and therefore, need to be conserved (IUCN 2015; Lindstrom and Hill, 2007; Mudannayake and Perera, 2014).

The genus Cycas has been examined by several researchers (de Laubenfels and Adema, 1998; Hill, 1994a \& b, 1995a \& b; Hill et al., 2004; Jones, 1993; Lindstrom and Hill, 2002, 2007; Smitinand, 1971, 1972). For the ease of identification and description, this genus has been divided into several subsections (Hill, 1995b, 2008; Lindstrom et al., 2008) despite that some researchers (de Laubenfels and Adema, 1998) disagree with divisions at subgeneric level. However, being a plant group which is difficult to identify to the species level at once, identification to subgeneric level would be helpful during field explorations. Six sections of this Genus have been recognized viz., Cycas Greuter, Asiorientales Schuster, Indosinenses Schuster, Stangerioides Smitinand (Hill, 1995a), Wadeae K. D. Hill and A. Lindstrom (Lindstrom et al., 2008) and Panzhihuaenses (D. Yue Wang) K. D. Hill (Hill, 2008). Among these, the section Cycas naturally

*Corresponding author's email: anomap@pdn.ac.lk 
occurs in Sri Lanka (Lindstrom and Hill, 2002). This section is further divided into three subsections: Cycas Greuter (Lindstrom and Hill, 2007), Endemicae Schuster (Hill, 1994c, Lindstrom and Hill, 2007) and Rumphiae K. D. Hill (Hill, 1994a, Lindstrom and Hill, 2007). Of these, Cycas and Rumphiae subsections are known to occur in Sri Lanka (Lindstrom and Hill, 2002) but, the subsection Endemicae is restricted only to Australia and the New Guinea (Lindstrom and Hill, 2007).

The history of cycad studies in Sri Lanka dates back to $18^{\text {th }}$ century with the first record of Sri Lankan cycads made by the distinguished scientist Carolus Linnaeus (1707- 1778) in his famous book, Flora Zeylanica (1747). According to Hill (1995), Linnaeus has cited treatments of Cycas from eight earlier works in the protologue of Cycas circinalis in 1753. He has treated these as a single element, C. circinalis L. (Lindstrom and Hill, 2002). About 100 years later, George Thwaites who served as the curator of the Royal Botanic Garden, Peradeniya from 1849 to 1880 , has collected material of some Sri Lankan Cycas species and distributed these to different European herbaria through William Barbey-Boissier (1842-1914) (Lindstrom and Hill, 2002). However, there are no records of their usage in taxonomic research during that era. Henry Trimen (1898) has also included C. circinalis in the Flora of Ceylon but there are no evidences of his collections of Sri Lankan Cycas species. Later, in 1932, based on the specimen collected by Thwaites, Schuster has differentiated the Sri Lankan material as $C$. nathorstii J. Schuster, endorsing the type of $C$. nathorstii from Sri Lanka (Thwaites 3689 in Schuster, 1932). According to Lindstrom and Hill (2002), Schuster's types were mainly in Berlin, Germany and may have been destroyed during the World War II. Later, de Laubenfels and Adema (1998) have again placed Sri Lankan material in the same taxon in $C$. circinalis in which the lectotype is from India. They have cited $C$. nathorstii J. Schuster as a synonym of $C$. sphaerica Roxb. but have not acknowledged $C$. sphaerica as a plant native to Sri Lanka.

In 2000, two Cycas species, C. circinalis L. emend J. Schust. and C. rumphii Miq. were recorded in the Revised Handbook to the Flora of Ceylon, with taxonomic descriptions of the two species (Wadhwa, 2000). However, soon after, in 2002, Lindstrom and Hill have confirmed the occurrence of $C$. nathorstii and C. zeylanica (J. Schuster) A. Lindstrom \& K. D. Hill in Sri Lanka, mainly based on the specimens in various herbaria in the world and also through field explorations for the latter species. The specimen collected in 1866 by Thwaites (no. 3689 in G) has been designated as the lectotype of $C$. nathorstii by Lindstrom and Hill (2002). In their description, they have cited that Cycas nathorstii (madu) which occurs in inland and upland forests in the northern parts of the island, usually in somewhat dry places, is an endemic plant to Sri Lanka while, Cycas zeylanica (maha madu) is restricted to the southern Sri Lanka and, the Andaman and Nicobar islands. Moreover, $C$. circinalis L. was considered as an endemic species to India (Hill, 1995). Accordingly, only $C$. nathorstii and $C$. zeylanica have been evaluated in the National Red List of Fauna and Flora of Sri Lanka in 2012 (National Red List, 2012) and, C. circinalis and C. rumphii in Sri Lanka remain unsubstantiated.

The past disagreements in taxonomic identification of Sri Lankan species may be partly due to the incomplete understanding of the Order Cycadales in that era and partly due to the unavailability of suitable Sri Lankan specimens for taxonomic research. Cycas species in Sri Lanka are not passably explored and hence the exact number of Cycas species of the country remains uncertain, urging the need for proper scientific exploration and description.

One of the major barriers for the conservation of Cycas species in Sri Lanka is the lack of information on the species identification and their distribution. Early records on the occurrence of different Cycas species are needed to be confirmed through extensive field explorations and taxonomic identification while investigating possible hybridization among species, if any. With this background, morphological, biochemical and molecular systematic studies of Sri Lankan Cycas species are being conducted at the Department of Botany, University of Peradeniya, Sri Lanka. However, the present paper is devoted only for the taxonomic identification of different Cycas taxa/species in Sri Lanka based on vegetative and reproductive morphological traits using available circumscriptions of the taxa, and to describe the characteristics of these taxa. A given morphological feature, especially the size of mature individuals or the magnitude of the vegetative and reproductive structures may vary from site to site which make the identification of individuals in the field rather difficult. Therefore, this study attempts to reveal taxonomically useful morphological features in distinguishing different Cycas taxa in Sri Lanka, to describe vegetative and reproductive morphology in Cycas species populations and, to develop keys for identification of Sri Lankan Cycas taxa. However, this paper does not intend to revise any accepted taxonomic circumscriptions of Cycas taxa.

\section{MATERIALS AND METHODS}

An island wide survey of Sri Lankan Cycads was carried out to find out different Cycas species present within the island. Forty nine morphological features (23 vegetative and 26 reproductive 
characters given in Tables 1 and 2), both qualitative and quantitative, in mature individuals were recorded and species were identified based on the available taxonomic descriptions of the taxa (Lindstrom and Hill, 2002, 2007). These characters were measured on fully mature individuals and structures. Some of the parameters measured are generally accepted norms in describing plant morphology but some other parameters have been specifically defined for comparing different Cycas species, and such used parameters are explained in the Box 1 below.

Two samples $t$ tests were performed using $\mathrm{R}$ commander 3.0.2 and $\mathrm{R}$ studio 0.98.501 statistical software to reveal significant differences of the examined quantitative morphological characters among different taxa. Taxonomic descriptions of the correctly identified Cycas species was prepared using important vegetative and reproductive features while the line diagrams were drawn to describe some of its morphological features.

\section{RESULTS}

A total of 435 individuals at different maturity stages were examined during field surveys and morphological traits were recorded in 181 mature individuals. Of these, 60 (48 female and 12 male) plants bore mature reproductive structures and only these were considered in identification of taxa in the present study. Results of the present study confirms the findings of Lindstrom and Hill (2002) that Cycas species in Sri Lanka represent both subsections of the Section Cycas, i.e., the subsections Cycas and Rumphiae and the occurrence of $C$. nathorstii (Figs. 1 \& 2) in Sri Lanka.

\section{Morphological features of taxonomic significance in differentiating Cycas taxa}

Several morphological features appeared to be helpful in distinguishing the subsection Cycas from that of Rumphiae. As Hill (1994a) stated, the presence of a layer of spongy endotests or a fibrous sarcotesta which are visible in a longitudinal section of a seed, is an important character in differentiating the two subsections. In the subsection Cycas, a fibrous sarcotesta exists but in the subsection Rumphiae, a spongy tissues are present in the endotesta. Thus, Cycas species in Sri Lanka too can be differentiated into subsections by this feature, but only the female individuals bearing seeds can only be identified using this feature. Therefore, the present study investigated other possible morphological traits in both male and female plants that can be used in distinguishing members of the subsection Cycas from those in the subsection Rumphiae in Sri Lanka and, are given in the Tables 1 and 2.

Some of the qualitative morphological characters, such as the shape of microsporophylls, megasprophylls and cataphylls appeared to be largely beneficial in differentiating the two subsections. Linear shaped cataphylls and upright apical spine of the microsporophylls in the individuals of the subsection Rumphiae can be used to distinguish these from the subsection Cycas, in which the apical spine of the microsporophylls is curved while the cataphylls are triangular in shape. Further, the narrowly ovoid pollen cone of the former group is different from ovoid-oblong pollen cones of the individuals in the subsection Cycas in Sri Lanka.

Box 1. Some of the specific morphological features used in describing Cycas species in the present study.

- Percentage spinescent (the length of the petiole with spines with respect to the total length of the petiole).

- Petiole circumference at the position of first leaflet.

- Petiole length + the lamina length as the full leaf length.

- Distance from one midrib to another of two adjacent leaflets at the central part of the leaf as a measure of leaflet spacing.

- Angle between median leaflets and rachis was considered as the insertion angle to rachis.

- Total length of the microsporophyll including the apical spine and width at the broadest point.

- Distance from the first ovule to the last ovule as the length of the fertile region.

- Distance from the last ovule to the apical spine as the length of the infertile region.

- Total length of the megasporophyll, i.e., the sum of lengths of fertile and infertile regions (the length from the base to the first ovule was not considered as it varies with the position of the megasporophyll on the tree).

- Total number of spines on both sides of the megasporophyll as the number of lateral spines.

- Colour of the sarcotesta as the seed colour.

- Presence of fibrous or spongy tissues/layers in the integument as seen in the transverse sections of seeds. 

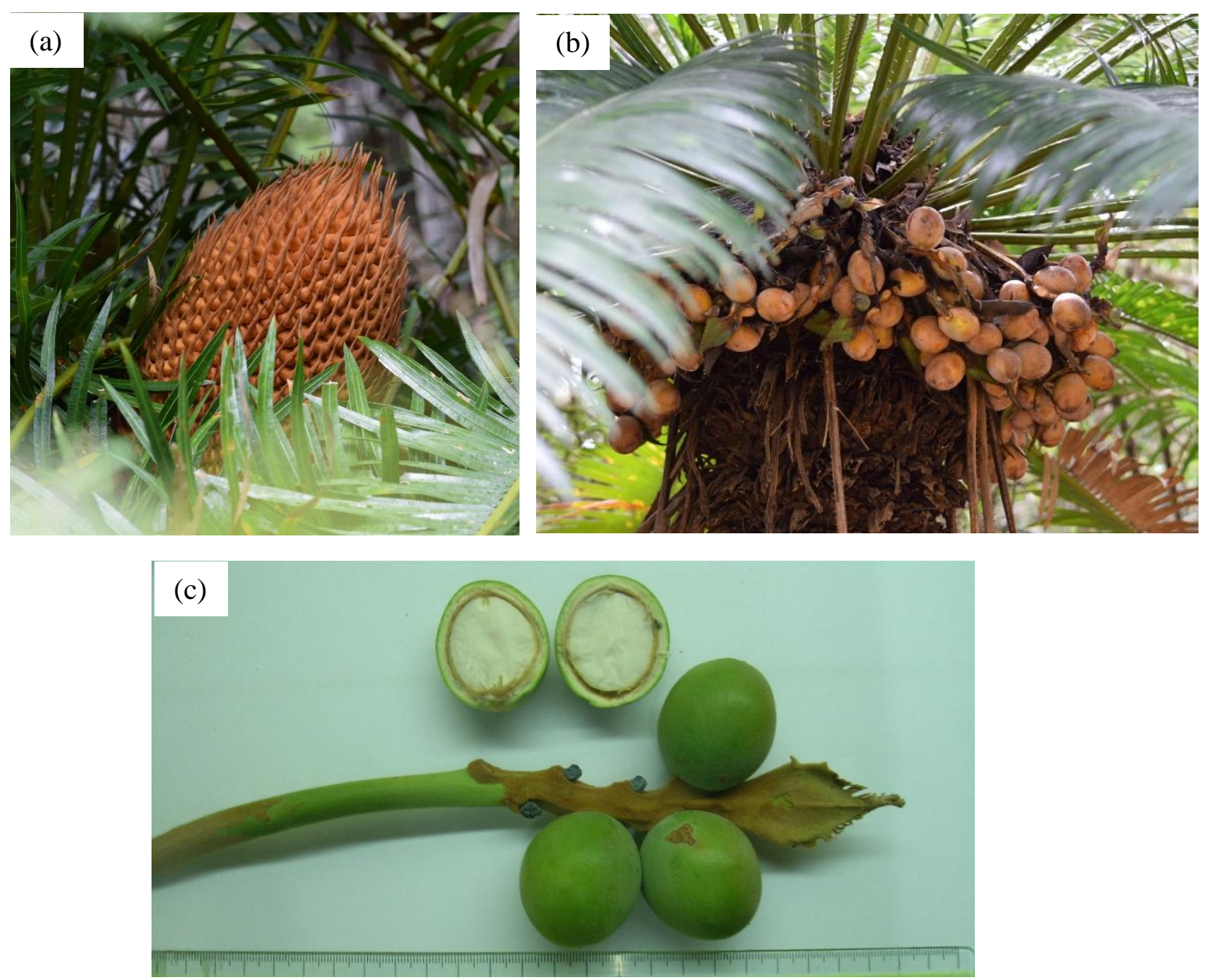

Figure 1. Cycas nathorstii (a) male cone (immature) (b) brownish orange mature seeds in a plant at Kudapathassa of Wilpaththu National Park (c) Megasporophyll with seeds and a longitudinal section of a seed

Of the 18 quantitative characters examined on reproductive structures, several (length:width ratio of microsporophylls, maximum width of the megasporophyll, the lengths of the fertile and infertile regions of megasporophylls, number of lateral spins on megasporophylls and the length of the apical spine) showed statistically significant differences between the two subsections but the ranges of values of these traits were overlapping between the two groups (Table 1). However, the total length of megasporophylls, the length:width ratio of the megasporphyll and length and width of seeds were significantly larger in the members of Rumphiae subsection than those in the subsection Cycas ( $t$ test $p<0.05$ ) and the ranges of values of these traits were not overlapping between the two groups. Therefore, these can be considered as prominent features in distinguishing the two taxa. The width of leaflets is the only morphological trait examined on vegetative structures which showed a significant differences ( $t$ test: $p<0.05$; Table 2) between the individuals of the two subsections without any overlapping between the two groups. In addition, the average values for the \% spinescent, total leaf length, length of petiole, petiole circumference, leaflet spacing, length of leaflets, width of leaflets, insertion angle to rachis and the cataphyll length, were significantly larger while the number of leaflets were significantly smaller in individuals of the subsection Rumphiae than those in the subsection Cycas ( $t$ test: $p<0.05$ ). However, these should be used with caution as there can be individuals in species populations bearing extremes of these characters resulting in overlapping limits among different taxa. Further, these limits of the taxa have to be revised upon the correct identification of all the Cycas species in Sri Lanka and then, these characters can be used in species identification with better confidence. 
Table 1. Comparison of morphology of reproductive structures in individuals of Cycas subsections in Sri Lanka. The numerical means of measured quantitative parameters are given with the range (within brackets) and the probability $(p)$ value of $t$ tests.

\begin{tabular}{|c|c|c|c|c|c|}
\hline & & \multirow{2}{*}{ Morphological trait } & \multicolumn{2}{|c|}{ Subsection } & \multirow[b]{2}{*}{$p$ value } \\
\hline & & & Cycas & Rumphiae & \\
\hline \multirow{7}{*}{ 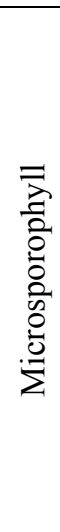 } & 1. & Microsporophyll length (cm) & $\begin{array}{l}5.61 \\
(4-8)\end{array}$ & $\begin{array}{c}6.95 \\
(6.6-7.3)\end{array}$ & 0.0770 \\
\hline & 2. & $\begin{array}{l}\text { Microsporophyll maximum } \\
\text { width }(\mathrm{cm})\end{array}$ & $\begin{array}{c}1.89 \\
(1.4-2.4)\end{array}$ & $\begin{array}{c}1.75 \\
(1.6-1.8)\end{array}$ & 0.3386 \\
\hline & 3. & $\begin{array}{l}\text { Microsporophyll length:width } \\
\text { ratio }\end{array}$ & $\begin{array}{c}2.99 \\
(1.25-3.81)\end{array}$ & $\begin{array}{c}3.97 \\
(3.8-4.1)\end{array}$ & 0.0027 \\
\hline & 4. & Apical spine length $(\mathrm{cm})$ & $\begin{array}{c}2.50 \\
(1.2-3.6)\end{array}$ & $\begin{array}{c}2.45 \\
(2.3-2.6)\end{array}$ & 0.8783 \\
\hline & 5. & Apical spine curved or upright & Curved & Upright & \\
\hline & 6. & Pollen cone shape & Ovoid-oblong & Narrowly ovoid & \\
\hline & 7. & Pollen cone colour & Brown & Pale fawn & \\
\hline \multirow{19}{*}{ 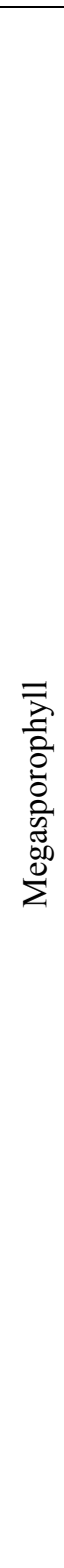 } & 8. & $\begin{array}{l}\text { Megasporophyll total length } \\
(\mathrm{cm})\end{array}$ & $\begin{array}{c}12.73 \\
(10.4-17)\end{array}$ & $\begin{array}{c}20.96 \\
(18-24)\end{array}$ & $<0.001$ \\
\hline & 9. & $\begin{array}{l}\text { Megasporophyll maximum } \\
\text { width }(\mathrm{cm})\end{array}$ & $\begin{array}{c}3.13 \\
(2.5-4)\end{array}$ & $\begin{array}{c}2.61 \\
(2.1-3.2)\end{array}$ & 0.0147 \\
\hline & 10. & $\begin{array}{l}\text { Megasporophyll length:width } \\
\text { ratio }\end{array}$ & $\begin{array}{c}4.14 \\
(2.5-5.7)\end{array}$ & $\begin{array}{c}8.13 \\
(6.25-10)\end{array}$ & $<0.001$ \\
\hline & 11. & Fertile region length $(\mathrm{cm})$ & $\begin{array}{c}6.04 \\
(4.1-12)\end{array}$ & $\begin{array}{c}8.75 \\
(7-12)\end{array}$ & 0.0223 \\
\hline & 12. & Number of ovules & $\begin{array}{c}6 \\
(5-8)\end{array}$ & $\begin{array}{c}5 \\
(4-6)\end{array}$ & 0.0064 \\
\hline & 13. & Infertile region length $(\mathrm{cm})$ & $\begin{array}{c}6.89 \\
(5-9.5)\end{array}$ & $\begin{array}{l}12.21 \\
(9-16)\end{array}$ & 0.0004 \\
\hline & 14. & Infertile region margin & Dentate & Entire to dentate & \\
\hline & 15. & Number of lateral spines & $\begin{array}{c}42 \\
(28-68)\end{array}$ & $\begin{array}{c}14 \\
(6-28)\end{array}$ & 0.0003 \\
\hline & 16. & Length of lateral spine (mm) & $\begin{array}{l}5.67 \\
(2-10)\end{array}$ & 4.37 & 0.4588 \\
\hline & 17. & Width of lateral spine (mm) & $\begin{array}{c}0.73 \\
(0.5-2.5)\end{array}$ & 0.875 & 0.6222 \\
\hline & 18. & Apical spine length (cm) & $\begin{array}{c}1.67 \\
(0.8-3.2)\end{array}$ & $\begin{array}{c}6.31 \\
(1-10.5)\end{array}$ & 0.0118 \\
\hline & 19. & Fertile to infertile ratio & $\begin{array}{c}1.25 \\
(0.42-1.73)\end{array}$ & $\begin{array}{c}1.50 \\
(0.8-2.28)\end{array}$ & 0.3355 \\
\hline & 20. & Seed length $(\mathrm{cm})$ & $\begin{array}{c}4.11 \\
(3.1-4.8)\end{array}$ & $\begin{array}{c}6.17 \\
(5.7-6.8)\end{array}$ & 0.0040 \\
\hline & 21. & Seed width $(\mathrm{cm})$ & $\begin{array}{c}3.32 \\
(2.8-4)\end{array}$ & $\begin{array}{c}5.37 \\
(5-6.2)\end{array}$ & 0.0086 \\
\hline & 22. & Seed length:width ratio & $\begin{array}{c}1.24 \\
(1.03-1.41)\end{array}$ & $\begin{array}{c}1.15 \\
(1.07-1.41)\end{array}$ & 0.0767 \\
\hline & 23. & Seed colour & $\begin{array}{l}\text { Yellow/Orange } \\
\text { brown }\end{array}$ & Orange brown & \\
\hline & 24. & Seed shape & Subglobose & Ovoid & \\
\hline & 25. & Fibrous layer in the sarcotesta & Present & Absent & \\
\hline & 26. & Spongy endocarp layer & Absent & Present & \\
\hline
\end{tabular}


Table 2. Comparison of morphological features of vegetative structures in individuals of Cycas subsections in Sri Lanka. The numerical means of measured quantitative parameters are given with the range (within brackets) and the probability $(p)$ value of $t$ tests.

\begin{tabular}{|c|c|c|c|c|}
\hline & \multirow{2}{*}{ Morphological trait } & \multicolumn{2}{|c|}{ Subsection } & \multirow{2}{*}{$p$ value } \\
\hline & & Cycas & Rumphiae & \\
\hline 1. & $\%$ spinescent & $\begin{array}{c}76.67 \\
(60-100)\end{array}$ & $\begin{array}{c}95.00 \\
(80-100)\end{array}$ & 0.0014 \\
\hline 2. & Petiole length $(\mathrm{cm})$ & $\begin{array}{c}45.83 \\
(32-69)\end{array}$ & $\begin{array}{c}74.58 \\
(45-112)\end{array}$ & 0.0020 \\
\hline 3. & Petiole circumference $(\mathrm{cm})$ & $\begin{array}{l}3.10 \\
(2-5)\end{array}$ & $\begin{array}{l}5.53 \\
(4-7)\end{array}$ & $<0.001$ \\
\hline 4. & Petiole length:circumference ratio & $\begin{array}{c}15.47 \\
(10.67-23.6)\end{array}$ & $\begin{array}{c}13.43 \\
(7.29-16.83)\end{array}$ & 0.2628 \\
\hline 5. & Leaf lamina length $(\mathrm{cm})$ & $\begin{array}{c}145.42 \\
(89-186)\end{array}$ & $\begin{array}{c}158.25 \\
(106-190)\end{array}$ & 0.3358 \\
\hline 6. & Full leaf length $(\mathrm{cm})$ & $\begin{array}{c}191.25 \\
(140-278)\end{array}$ & $\begin{array}{c}232.83 \\
(157-292)\end{array}$ & 0.0363 \\
\hline 7. & Number of leaflets & $\begin{array}{c}201 \\
(156-266)\end{array}$ & $\begin{array}{c}131 \\
(98-184)\end{array}$ & $<0.001$ \\
\hline 8. & Leaflet spacing $(\mathrm{cm})$ & $\begin{array}{c}1.55 \\
(0.8-2)\end{array}$ & $\begin{array}{c}3.23 \\
(1.5-4)\end{array}$ & 0.0004 \\
\hline 9. & Leaflet length $(\mathrm{cm})$ & $\begin{array}{c}22.17 \\
(16-31)\end{array}$ & $\begin{array}{c}32.55 \\
(27.3-37.5)\end{array}$ & $<0.001$ \\
\hline 10. & Leaflet width $(\mathrm{cm})$ & $\begin{array}{c}0.99 \\
(0.9-1)\end{array}$ & $\begin{array}{c}1.57 \\
(1.2-1.8)\end{array}$ & $<0.001$ \\
\hline 11. & Leaflet length:width ratio & $\begin{array}{c}22.39 \\
(16-27)\end{array}$ & $\begin{array}{c}20.97 \\
(17.2-25)\end{array}$ & 0.2933 \\
\hline 12. & Midrib above & Raised & Raised & \\
\hline 13. & Midrib below & Raised - Flat & Flat & \\
\hline 14. & Leaflet margin & Entire & Entire & \\
\hline 15. & Leaflet apex & Acuminate & Acuminate & \\
\hline 16. & Insertion angle to rachis & $\begin{array}{c}51.67 \\
(45-80)\end{array}$ & $\begin{array}{c}72.92 \\
(45-80)\end{array}$ & 0.0002 \\
\hline 17. & Cataphyll shape & Triangular & Linear & \\
\hline 18. & Cataphyll length $(\mathrm{cm})$ & $\begin{array}{c}6.67 \\
(6-9.5)\end{array}$ & $\begin{array}{l}12.77 \\
(7-17)\end{array}$ & $<0.001$ \\
\hline 19. & Cataphyll-persistent or shedding & Persistent & Persistent & \\
\hline 20. & Leaflet colour - mature & Dark green & Dark green & \\
\hline 21. & young leaves - colour & $\begin{array}{c}\text { Light } \\
\text { green/Bluish } \\
\text { green }\end{array}$ & Light green & \\
\hline 22. & Tomentum & Present & Present & \\
\hline 23. & Tomentum colour & Brown & Golden brown & \\
\hline
\end{tabular}

Moreover, the shape of cataphylls, upright/curved nature of the apical spine of microsporophylls, shape of pollen cone are important qualitative features in differentiating individuals of the two subsections.

The present study revealed that some samples collected from individuals of the subsection Cycas show clear similarities to $C$. nathorstii. Further, it is easy to differentiate $C$. nathorstii from those in the subsection Rumphiae by their external morphology. The length of the leaflets in the former is significantly shorter than in the latter ( $t$ test: $p=0.00004)$. Also, the midrib beneath the leaflets is raised in $C$. nathorstii but it is flat in C. rumphii complex. The number of lateral spines is significantly higher while the lengths of the fertile and infertile regions of megasporophylls are significantly lower in $C$. nathorstii than in 
C. rumphii complex in Sri Lanka (t test: number of lateral spines, $p=0.009$; the length of the fertile region, $p=0.0029$ and the length of the infertile region, $p=0.0002$ ).

Cycas zeylanica (J.Schust.) A.Lindstr. \& K.D.Hill is reported as a native species occurring in southern coastal regions of Sri Lanka (Lindstrom and Hill, 2002), growing in littoral forests near the sea in sandy soil and are often found on stabilized dunes (Lindstrom and Hill, 2002; IUCN Red List, 2015). During our field explorations, a few individuals that suspected to be $C$. zeylanica were found but these were not bearing reproductive structures at that time.
Therefore, the morphological features of the species has not adequately being assessed and therefore, the species is not being described in this paper. Further, the individuals examined in the subsection Rumphiae showed a wide variations indicating the presence of several species or varieties.

Keys to the identification of subsections of $\boldsymbol{C y c a s}$ With an intension of easy identification of Sri Lankan Cycas taxa during field explorations, keys have been prepared including all remarkable characteristic features of taxonomic significance in vegetative and reproductive structures of both male and female plants.

\section{Order Cycadales, Section Cycas in Sri Lanka}

1 Width of leaflets $0.9-1 \mathrm{~cm}$; cataphylls triangular; apical spine of the microsporophyll curved; ovoid-oblong pollen cone; megasporophyll 10-17 cm long, megasporophyll length:width ratio $2.5-5.7 \mathrm{~cm}$, number of lateral spines 28-68; subglobose seeds, not very large $(3.1-4.8 \mathrm{~cm} \times 2.8-4 \mathrm{~cm})$ with a fibrous sarcotesta, no spongy tissues in the endotesta.

Subsection: Cycas

1 Width of leaflets $1.2-1.8 \mathrm{~cm}$; cataphylls linear in shape; apical spine of the microsporophyll upright; narrowly ovoid pollen cone; megasprophyll $18-24 \mathrm{~cm}$ long, megasporophyll length:width ratio $6.25-10 \mathrm{~cm}$, number of lateral spines 6-28; Ovoid seeds, larger $(5.7-6.8 \mathrm{~cm} \times 5-6.2 \mathrm{~cm})$ with spongy tissues in the endotesta, no fibrous sarcotesta.

Subsection: Rumphiae

Descriptions of species based on vegetative and reproductive morphology of species populations Both vegetative and reproductive features of the population of $C$. nathorstii recorded during field explorations are given in the descriptions below. Although the authors have not seen the types, the circumscriptions by Hill (1995b) and Lindstrom and Hill (2002) have mainly been followed.

\section{C. nathorstii J. Schuster}

Vernacular: Madu (S)

Perennial trees, Stems arborescent, sometimes forked, bark thick and corky with persistent cataphylls and leaf bases. Petiole glabrous, $32-56 \mathrm{~cm}$ long with $60-100 \%$ of spinescent. Mature leaves dark green, semi glossy, 108-186 cm long, flat (not keeled) in section with 156-246 leaflets. Light brown tomentum shedding as leaf mature. Median leaflets simple, lanceolate, $16-24 \mathrm{~cm}$ long and $0.9-1 \mathrm{~cm}$ wide, 1.3-2.0 cm spacing on rachis; entire margin with acuminate apex. Midrib raised above and slightly raised below. Cataphylls narrowly triangular and 6-7.2 $\mathrm{cm}$ long. Male cone brown and ovoid to conical shape when immature, more elongated when mature. Microsporophyll lamina firm; ovoid to deltoid but narrows gradually; $4-5.5 \mathrm{~cm}$ long and 1.4-1.9 $\mathrm{cm}$ wide; apical spine prominent, curved with 1.2-3.6 cm in length. Megasporophyll possesses orange tomentum; fertile region $4.1-6.5 \mathrm{~cm}$ long; infertile region $5.4-7.0 \mathrm{~cm}$ long and $2.5-3.4 \mathrm{~cm}$ wide; ovules 5-7, glabrous; infertile region shortly dentate with 34-68 lateral spines, 2-5 mm long and 1 $\mathrm{mm}$ wide at base. Seeds subglobose, 3.1-4.8 cm long, 3.1-3.4 cm wide; sarcotesta orange brown, fibrous; spongy endotesta absent.

\section{Notes on the subsection Cycas in Sri Lanka}

Individuals of the subsection Cycas examined showed a wide variation in their morphological features (Tables 1 and 2). As a result, the ranges of some quantitative traits were broader. However, some of the collected material looks similar to the circumscriptions of $C$. nathorstii. Wide and distinct variations of examined morphological parameters within this subsection indicates the presence of different taxa within this subsection, at species or variety levels, or possible hybridization among different taxa. Therefore, it is necessary to study these further for clear clarification and identification of Cycas taxa in this subdivision. However, the morphological features of Sri Lankan samples do not match with $C$. circinalis (Personal communications with Dr A. J. Lindstrom, the Nong Nooch Tropical Gardens, Sattahip, Thailand) and therefore, there is a high possibility that $C$. circinalis does not naturally grow in Sri Lanka. 
(a)

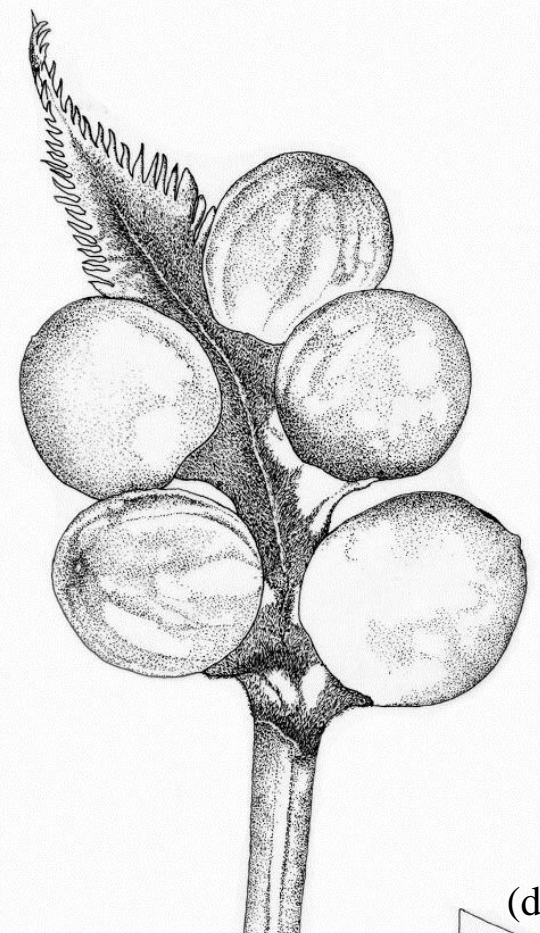

(d)

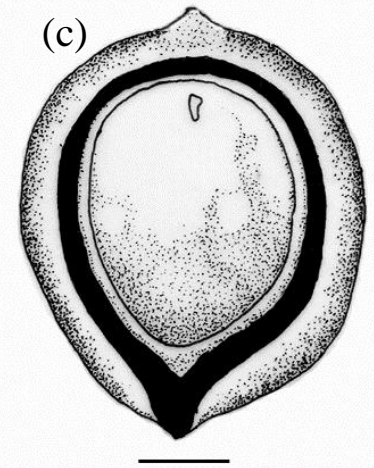

(b)

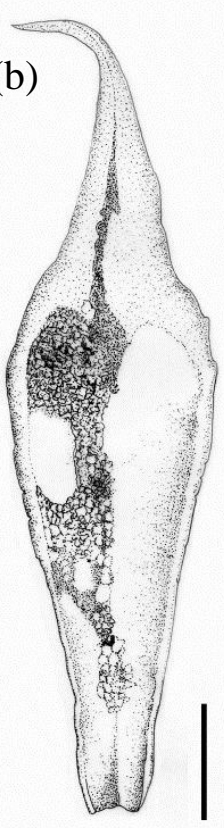

(e)

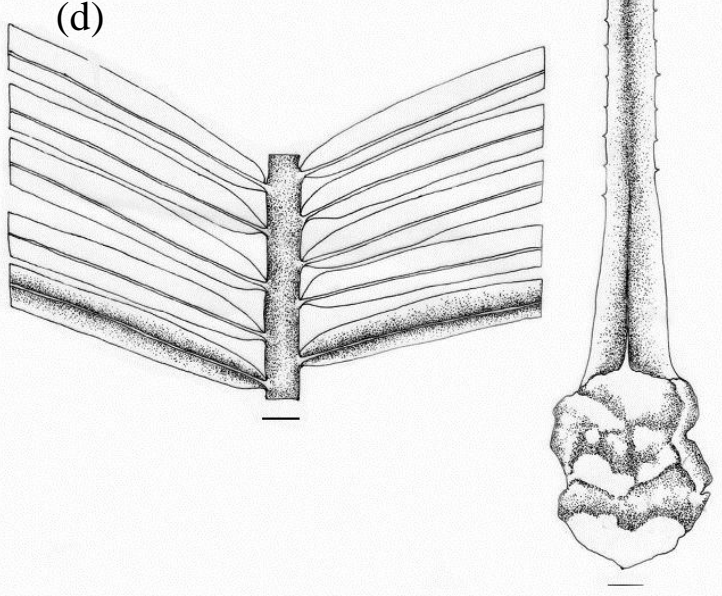

(f)

Figure 2. Cycas nathorstii (a) megasporophyll from a middle whorl, (b) a microsporophyll, (c) Longitudinal section of a seed, (d) median leaflets showing the insertion angle to rachis (e) petiole and (f) a leaflet [scale bar $=1 \mathrm{~cm}$ ]

In the past, there were some instances which reported C. circinalis in Sri Lanka (Linnaeus, 1753, Trimen 1898 and Wadhwa, 2000). Hill (1995b) has clearly pointed out that it was designated as the single constituent species when Linnaeus established the genus Cycas and therefore, the name of $C$. circinalis has often been used in the past in an aggregate sense. Of the eight references cited by Linnaeus (1753) in the protologue of C. circinalis, only two have now been typified as $C$. circinalis (Lindstrome and Hill, 2007). Later, some of the specimens collected from Sri Lanka, which formerly identified as $C$. circinalis have been treated as $C$. nathorstii by Schulster, and the specimen collectd by Thawaites (no. 3689) was considered as the isosyntype of Cycas nathorstii (Lindstrom and Hill, 2002). However, de Laubenfels and Adema (1998) have continuously considered Sri Lankan Cycas 
species as $C$. circinalis and, they cited $C$. nathorstii under the synonym of $C$. spherical, which is not acknowledged as a native Sri Lankan species. When preparing the Revised Handbook to the Flora of Ceylon, Wadhwa (2000) has also reported the presence of $C$. circinalis in Sri Lanka but has not acknowledged the occurance of $C$. nathorstii in Sri Lanka. Once Lindstrom and Hill (2002) cited the occurrence of $C$. nathorstii as a species endemic to Sri Lanka, while acknowledging $C$. circinalis as an endemic species in India which restricted to Western Ghats, Kerala, Karnataka, Tamil Nadu and the Rajasthan (Lindstrom and Hill, 2002), the occurrence of $C$. circinalis in Sri Lanka was treated as a misidentification and therefore, largely neglected. The specimens used by Wadhwa (2000) for preparing the section Cycadaceae for the Revised Handbook to the Flora of Ceylon are available at the Kew Gardens herbarium, but of these, duplicates of Jayasuriya 1278 from the ridges of Na-Ulpotha of the Ritigala Strict Nature Reserve and Hepper \& G. de Silva 4723 from Bibile are available in the PDA herbarium at present. These have not probably been seen by Wadhwa as no annotations were made on the herbarium sheets. Of these, the former has been labeled as Cycas cf. circinalis while the latter has been identified only to the genus level by collectors, urging the necessity of further identification. Wadhwa (2000) has identified these two in the Kew Gardens as $C$. circinalis while Lindstrom and Hill (2002) differentiated these as $C$. nathorstii. However, the corresponding author of this article (AP) noted that the duplicates of these in the PDA herbarium are not in a good condition to come to a strong conclusion. In addition, there were three other specimens in PDA which have not been included in the Revised Handbook to the Flora of Ceylon. Among these, the specimen by F. N. Hepper \& G. de Silva 4723 from Bibile has not been identified to the species level. Two other specimens, i.e., F.R. Fosberg \& M.-H. Sachet 53148 collected from 2 miles east of Bibile and Sohmer \& D.B. Sumithrarachchi 10,711 collected from Timbiriyawila were female plants with megasporophylls and were labelled as $C$. circinalis but the taxonomic identification of these specimens remained questionable. Lindstrome and Hill (2002) recorded that the duplicate of the former (F.R. Fosberg \& M.-H. Sachet 53148) in the Kew Gardens and New York Herbaria as $C$. nathorstii while AP noted that the latter specimen (Sohmer \& D.B. Sumithrarachchi 10,711) signifies more towards $C$. nathorstii. However, the other specimens observed by Lindstrom and Hill (2002) are not available in the PDA herbarium.

Notes on the subsection Rumphiae in Sri Lanka About 11 species are reported worldwide under the subsection Rumphiae in the Genus Cycas (Lindstrom and Hill, 2002) but the taxonomy of this group is difficult and unclear (Hill 1994). All species in the C. rumphii complex have been erroneously cited as $C$. circinalis at some stage (Hill 1994; Lindstrom and Hill, 2002). Cycas rumphii Miq. has been separated from $C$. circinalis $\mathrm{L}$. by Miquel in 1839 (Lindstrom and Hill, 2007).

The individuals examined in the subsection Rumphiae in Sri Lanka showed a wide but consistent variation and need further investigations to identify and describe these at species level. Some of the morphological traits considered in the Tables 1 and 2 show drastic variations resulting a wider ranges of examined quantitative characters. It is obvious that there could be more than one species or many intermediate forms in this group too. Consequently, the overall distribution of the different species is not clear. Therefore, thorough field explorations and molecular characterization of the group are required before determining the limits of Cycas species in this subsection and these investigations are currently being carried out at the Department of Botany, University of Peradeniya, Sri Lanka.

Two species of the $C$. rumphii complex have been reported in Sri Lanka so far; viz. C. rumphii Miq. (Wadhwa, 2000) and Cycas zeylanica (Lindstrom and Hill 2002). Of these, C. zeylanica is listed as a Globally Vulnerable species due to the overall decline in the population size $(30-50 \%$ reduction in the last 50 years alone). Populations in the wet zone of Sri Lanka have been categorized as reduced and Extinct in the Wild, but the species is reported as still relatively abundant in the Indian parts of its range, i.e., on the Andaman and Nicobar islands (Lindstrom and Hill, 2002; IUCN, 2015). During our field explorations, we were able to locate a few individuals of the species but no natural populations were noticed. Further, no male plants of $C$. zeylanica were found so far. However, the occurrence of $C$. rumphii in Sri Lanka has not been confirmed so far by other scientists.

\section{Identification of Cycas taxa based on morphological traits}

Identification of Cycas species based on morphological features observed in herbarium specimens may be a difficult task. In general, the morphological traits may vary from region to region or from one country to another, the age of the plant or the position of the sample (plant part) on the plant. For instance, in the subsection Cycas, the megasporophylls in the lower whorls contain a broader infertile region with more regular lateral teeth whereas those in the upper whorls are less broad with irregular lateral teeth and a long apical spine. Therefore, we propose to develop norms describing the morphological traits of Cycas species. It is very helpful if details of the maturity stage and the position of the micropsporophyll within the pollen cone or the megasporophyll within the tree (lower or upper whorl) are provided on herbarium 
specimens. Further, it is worth to consider as many traits as possible in the identification of Cycas taxa and, include many traits when preparing identification keys of Cycas taxa. To avoid confusions, it is much easier and more practical if the examining individuals are first identified to subsection levels and then proceeded with species level identification.

We have further observed that most of the collectors tend to collect immature reproductive structures of Cycas species in preparing herbarium specimens, especially the megasporophylls with ovules, as those with seeds are bulky and crooked. Some of the significant morphological traits may not have fully developed in these immature plant parts. All these have made the identification and description of Cycas species using herbarium specimens, a more dubious task. Recent advancements of molecular phylogenetic studies would help in correct identification of Cycas species however, these may not be a solution for quick recognition of species during field explorations. Therefore, the morphological traits that help in identifying Cycas species have to be investigated further.

\section{Concluding remarks}

Cycas species in Sri Lanka represent both subsections Cycas and Rumphiae of the section Cycas. However, the present paper only confirms the C. nathorstii in the subsection Cycas as a native endemic to the country. Although, $C$. zeylanica is reported from Sri Lanka (Lindstrom and Hill, 2002), it is not considered in the present paper due to insufficient amount of collected material during our field explorations. Moreover, further taxonomic research are required in confirming or identifying the occurrence of other Cycas species in Sri Lanka.

It appears that most of the taxonomic work on Sri Lankan Cycas taxa were based on a few herbarium material collected in the past (e.g. George Thwaites) which are located in different herbaria in the world. No detailed field explorations have been conducted to represent the species diversity of the country and no taxonomic studies have been conducted to elucidate the species limits of Sri Lankan Cycas species. Therefore, all Cycas taxa of Sri Lanka may not have been acknowledged in the past for taxonomic revisions. The inherent difficulties in identifying different Cycas species using morphological features and the dubious nature of collected specimens in early times might also responsible for that.

Taxonomically useful morphological features in distinguishing different Cycas subsections in Sri Lanka and in identifying $C$. nathorstii were revealed from the current study. Shape of cataphylls, upright/curved nature of the apical spine of microsporophylls, shape of pollen cone, length of megasporophylls, length:width ratio of the megasporophyll, length and width of seeds and, width of leaflets can be considered as important traits of taxonomic significance which allows to distinguish the individuals of the subsection Rumphiae from the subsection Cycas in Sri Lanka. Several other quantitative features show significant differences among the taxa but ranges (based on maximum or minimum values) of these characters may sometimes overlap among the taxa examined. Therefore, these have to be considered carefully with other suitable characters in identifying Cycas taxa. Moreover, the limits of the taxa have to be revised upon the correct identification of Cycas species in Sri Lanka and, subsequently, these traits can be useful in taxonomic identification of Cycas species in the country. Different Sri Lankan Cycas species share many common features and therefore, it is always advised to differentiate the two subsections of the genus first, before attempting to identify the species straight away. Further, molecular characterization of Sri Lankan cycads is required to identify all the Cycas species and their intermediate forms in Sri Lanka, and to describe their biogeographic affinities. These studies are currently being conducted at the Department of Botany, University of Peradeniya, Sri Lanka.

\section{ACKNOWLEDGMENTS}

Financial assistance for the research granted by the University of Peradeniya (Research Grant No.: $\mathrm{RG} / 2013 \mathrm{AF} / 72 \mathrm{~S}$ ) is gratefully acknowledged. The authors also wish to thank the Forest Department of Sri Lanka and the Department of Wildlife Conservation, Sri Lanka for granting permission to collect material for this research from protected areas and forest reserves of Sri Lanka, Ms Y. Dilhani and Mr C. Alahakoon of the Department of Botany, University of Peradeniya for helping in the field, $\mathrm{Mr}$ Indika Paebotuwage for drawing taxonomic diagrams. Dr Sumudu Rubasinghe and Ms Buddhie. Nanayakkara of the Department of Botany, University of Peradeniya for the valuable suggestions made on the manuscript. Our special gratitude goes to Dr A. J. Lindstrom of the Nong Nooch Tropical Gardens, Sattahip, Thailand for clarifications made on debatable points in species identification and for his valuable comments on the manuscript.

\section{REFERENCES}

De Laubenfels D. J, and Adema F. (1998). A taxonomic revision of the genera Cycas and Epicycas gen. nov. (Cycadaceae). Blumea 43: 351-400.

Hill, K. D. (1994a). The Cycas rumphii complex 
(Cycadaceae) in New Guinea and the Western Pacific. Australian Systematic Botany 7(5): 543567.

Hill, K.D. (1994b). The golden cycad of Fiji. Encephalartos 38: 11-13.

Hill, K. D. (1994c). The Cycas media group (Cycadaceae) in New Guinea. Australian Systematic Botany 7: 527-541.

Hill, K. D. (1995a). Infrageneric relationships, phylogeny and biogeography of the genus Cycas (Cycadaceae). In: Vorster P (ed.) CYCAD 93, The 3rd International Conference on Cycad Biology, Proceedings. (Cycad Society of South Africa: Stellenbosch) Pp 139-162.

Hill, K. D. (1995b). The genus Cycas (Cycadaceae) in the Indian Region, with notes on the application and typification of the name Cycas circinalis. Taxon, 44 (1): 23 - 31.

Hill, K. D., Chen, C.J. and Loc, P.K. (2003). Regional overview: Asia. In: Cycads. Status Survey and Conservation Action Plan. IUCN/SSC Cycad Specialist Group. ed. Donaldson, J.S. IUCN, Gland, Switzerland and Cambridge, UK, Chapter 5, 25-30.

Hill, K. D. Nguyen, H. T. and Loc, P. K. (2004). The Genus Cycas (Cycadaceae) in Vietnam. Botanical Review 70(2): 134-193.

Hill, K. D. (2008). The genus Cycas (Cycadaceae) in China. Telopea 2(1): 71-118.

Jones, D. L. (1993). Cycads of the world. Chatswood.

Lindstrom A. J. and Hill, K. D. (2002). Notes on the species of Cycas (Cycadaceae) from Sri Lanka and Islands of the Andaman Sea. Novon 12(2): 237-240.

Lindstrom, A. J. and Hill, K. D. (2007). The genus Cycas (Cycadaceae) in India. Telopea 11(4): 463-488.

Lindstrom, A. J., Hill, K. D. and Stanberg, L. C. (2008). The genus Cycas (Cycadaceae) in the Philippines. Telopea 12 (1): 119-145.

Linnaeus, C. (1747). Flora Zeylanica. (Holmiae [Stockholm]: L. Salvii).
Linnaeus, C. (1753). Species Plantarum, vol. 1 (1960 facsimile). (Engelmann: Weinheim).

Mamay, S. H. (1969). Cycads: Fossil evidence of late Paleozoic origin. Science 164: 295-296.

Mudannayake, M. M. A. W. P. and Perera, G. A. D. (2014). Ethno-botanical perspectives for the conservation and sustainable utilization of Sri Lankan cycads (Madu). Proceedings of the Tropical Ecology Congress 2014, Jawaharlal Nehru University New Delhi and International Society for Tropical Ecology, India.

Osborne, R., M. A. Calonje, K. D. Hill, L. Stanberg and D. W. Stevenson. (2012). The World List of Cycads. In: Proceedings of the 8th International Conference on Cycad Biology (CYCAD 2008), January 2008, Panama, City, Panama, Memoirs of the New York Botanical Garden 106: 480-510.

Schuster, J. (1932). Cycadaceae. In: Engler A (ed.) Das Pflanzenreich 99(4,1). (Engelmann:Leipzig) Pp. 1-168.

Smitinand, T. (1971). The genus Cycas Linn. (Cycadaceae) in Thailand. Natural History Bulletin of the Siam Society 24, 163-175.

Smitinand T. (1972). Cycadaceae. Flora of Thailand 2: 185-192.

Stevenson, D. W. (1992). A formal classification of the extant cycads. Brittonia 44: 220-223.

IUCN. (2015). The IUCN Red List of Threatened Species. 2015. Version $2015.2 \mathrm{http} / / \mathrm{www}$. iucnredlist.org/ details/42098/0. Downloaded on 01 June 2015.

National Red List. (2012). The National Red List 2012 of Sri Lanka: Conservation status of the Fauna and Flora. (2012). The Biodiversity Secretariat and The Department of National Botanic Gardens, Sri Lanka.

Trimen, H. 1898. Flora of Ceylon. vol. 4. Dulau, London.

Wadhwa, B. M. (2000). Cycadaceae. In: M. D. Dassanayake \& W.D. Clayton (eds.) A revised handbook to the Flora of Ceylon, Vol. xiv, Oxford \& IBH Publishing Co. Pvt. Ltd., New Delhi, India. Pp. 300- 304. 